The University of San Francisco

USF Scholarship: a digital repository @ Gleeson Library |

Geschke Center

Philosophy

College of Arts and Sciences

Fall 2011

\title{
Arthur Pap's Functional Theory of the A Priori
}

David J. Stump

University of San Francisco, stumpd@usfca.edu

Follow this and additional works at: http://repository.usfca.edu/phil

Part of the Philosophy Commons

\section{Recommended Citation}

Stump, David J., "Arthur Pap's Functional Theory of the A Priori" (2011). Philosophy. Paper 15.

http://repository.usfca.edu/phil/15

This Article is brought to you for free and open access by the College of Arts and Sciences at USF Scholarship: a digital repository @ Gleeson Library | Geschke Center. It has been accepted for inclusion in Philosophy by an authorized administrator of USF Scholarship: a digital repository @ Gleeson

Library | Geschke Center. For more information, please contact repository@usfca.edu. 


\title{
ARTHUR PAP'S FUNCTIONAL THEORY OF THE A PRIORI
}

\author{
David J. Stump
}

Arthur Pap was not quite a Logical Empiricist. He wrote his dissertation in philosophy of science under Ernest Nagel, and he published a textbook in the philosophy of science at the end of his tragically short career, but most of his work would be classified as analytic philosophy. More important, he took some stands that went against Logical Empiricist orthodoxy and was a persistent if friendly critic of the movement. Pap diverged most strongly from Logical Empiricism in his theory of a "functional a priori" in which fundamental principles of science are hardened into definitions and act as criteria for further inquiry. Pap was strongly influenced by the pragmatists C. I. Lewis and John Dewey in developing this alternative theory of a priori knowledge. Using Poincarés conventionalism as a springboard, Pap attempted to substantiate these views with examples from physics, and this was his largest foray into philosophy of science topics. Pap, as well as Lewis and Dewey, developed an alternative theory of the a priori in the 1950 s that never quite took hold, despite the fact that their views are very intriguing and similar to Michael Friedman's recent work on the constitutive a priori.

\section{Pap, the Man and His Work}

Arthur Pap shares a history with the Vienna Circle, although of course he was not a member. Like many members of the Vienna Circle, Pap was a European Jew whose family fled the Nazis, an immigrant scholar with a background in science as well as philosophy. He was younger, so his university education took place in the United States, first at Columbia, then at Yale for a master's degree under Ernest Cassirer, and then back at Columbia for his PhD under Ernest

David J. Stump is professor, University of San Francisco, 2130 Fulton Street, San Francisco, CA 94706 (stumpd@usfca.edu).

I would like to thank the audience at HOPOS 2008, where a version of this article was first read, and two anonymous reviewers for this journal for helping me clarify several points.

HOPOS: The Journal of the International Society for the History of Philosophy of Science, vol. 1 (Fall 2011). 2152-5188/2011/0102-0005\$10.00. (C) 2011 by the International Society for the History of Philosophy of Science. All rights reserved. 
Nagel. Cassirer and Nagel were two more immigrant Jews who were interested in both science and philosophy. Cassirer was a neo-Kantian, Nagel was influenced by pragmatism, and each of these movements had a strong influence on Pap at the start of his remarkable career. He published a pair of articles in the Journal of Philosophy (1943a, 1943b) and one in Philosophical Review (1944) before completing his dissertation, which won an award and was immediately published (1946). In the course of his short career, he published five books and over 50 articles before dying of kidney disease at age 37 .

I am most interested here in Pap's work on the functional (or pragmatic) theory of the a priori, which he develops in his dissertation, applying it especially to Newtonian physics. In Pap's theory of a "functional a priori," fundamental principles of science are hardened into definitions and act as criteria for further inquiry. In developing this alternative theory of what had formerly been a priori knowledge, Pap was strongly influenced by the pragmatists C. I. Lewis (1923/1970, 1929/1956) and John Dewey (1938/1986). Using Poincaré's conventionalism as a springboard, Pap attempted to substantiate his view with examples from physics, thus making his most significant foray into philosophy of science topics. Pap is of special interest in that while he was a fellow traveler and was writing in the heyday of Logical Empiricism, his philosophy of science took a pragmatic turn, although by the time that Pap was writing, pragmatism had already been eclipsed. As we will see, there is a direct line of descent from Pap to Lenzen, C. I. Lewis, and Dewey and from Dewey to Peirce.

Nonetheless, Pap did not remain in the philosophy of science for long. After his dissertation, most of his work is more generally in analytic philosophy, not in the philosophy of science per se. He returned to philosophy of science only to write a textbook at the end of his career. Still, he is of interest to philosophers of science. Pap, and through him Lewis and Dewey, constituted an alternative philosophy of science in the 1950s that never quite took hold, despite the fact that their views on the a priori are very intriguing and quite similar to Michael Friedman's recent work on the constitutive a priori (2001). Of course, there is more than this one version of the Vienna Circle-inspired Logical Empiricism. George Reisch has shown how Philip Frank and Otto Neurath, the left wing of the Vienna Circle, presented another alternative philosophy of science to that established in the 1950s (Reisch 2005).

Pap's debt to pragmatism goes beyond the influence that C. I. Lewis had on him with his pragmatic theory of the a priori. Pap also drew directly on Dewey, as we can see in his numerous citations of Dewey and in his use of a phrase taken from Dewey that is important in making the connection between temporal change and the status of fundamental principles in science. Dewey says of fundamental principles that "while they are derived from examination of 
methods previously used in their connection with the kind of conclusion they have produced, they are operationally a priori with respect to further inquiry" $(1938 / 1986,21)$. In a footnote, Dewey calls his assertion "a free rendering of Peirce" and cites two passages in Peirce's collected papers (1958-60, vol. 3, par. 154-68, and vol. 5, par. 365-70). Pap quotes part of this phrase from Dewey without citation in his 1944 article $(1944,2006,72)$, as if he were quoting from memory. In his dissertation, Pap again quotes Dewey, again without citation, but this time he uses a slightly different phraseology: "Hooke's law remains refutable by experience, even though it may provisionally function as 'a priori with respect to further operations,' in Dewey's phrase" (1946, 30). Since Pap quotes Dewey without a citation, it is hard to know whether he has just misremembered Dewey's phrase that he quoted earlier or whether he has some other passage in Dewey in mind. Given that Logic (1938/1986) is the only work of Dewey's that is cited in Pap's bibliography in his dissertation and that Dewey's phrase only exists in Logic as quoted above, it seems likely that Pap has given this quotation from memory and that he has not gotten Dewey's phrase exactly correct. The lack of citations in the two passages is unusual for Pap and could represent a special familiarity with Dewey's work, as if Dewey were on his mind while writing. The phrase and the idea that it represents obviously impressed Pap, given that he quotes it in two different works.

In Dewey as in Pap, what starts out as empirical knowledge ends up being fixed and taken for granted, that is, it functions as a priori knowledge. Most important to note is the temporal aspect of the a priori in this conception-that is the point of the "with respect to further operations [or inquiry]" language. A functionally a priori principle started out as provisional and empirical and will be treated as a priori at some other point in time or in some other context. On this view, everything is ultimately provisional, but some elements of our knowledge must be taken as fixed at a given point in order to pursue further inquiry. As Pap emphasizes in the introduction to his work, this temporal aspect of functionally a priori knowledge is the crucial point that allowed him to see his way out of his discomfort over the positivists' treatment of the a priori. The same statement can play a very different role in a scientific theory at different times. Mutatis mutandis, the same temporal solution can be applied to the problem of distinguishing between analytic and synthetic statements, given that what was once synthetic can be taken to be analytic and what was once analytic, in being questioned, can be taken as synthetic and empirical, at a different time and in a different context.

Pap explicitly acknowledges the lineage of influences that permeates his dissertation. He is working with a particular interpretation of Poincaré, that given by Victor Lenzen (1931), and with Lewis and Dewey's pragmatic conceptions 
of the a priori, which leads him to view functionally a priori principles as empirical laws that have been taken to be definitions and function as categorical principles or constitutive conditions. "As the motto which is prefixed to this essay indicates, Poincaré's 'conventions' (in mechanics) are principles that have been 'derived' from experimental laws_-in much the same way as our 'real definitions' are thus derived — at the same time, however, [they] have been immunized against possible invalidation by future experience. They function like Lewis' 'categorial principles,' in so far as, if an experience does not fit them, 'so much the worse for the experience.' Our emphasis on this conventionalization of inductive generalisations has been greatly influenced by Victor Lenzen's detailed application of Poincaré's notion of 'conventions' to physical theory" (Pap 1946, 21). It is important to note that the conventionalism mentioned here is that of the principles of mechanics, not Poincaré's geometric conventionalism, which has a different source. Lenzen has a pragmatic interpretation of Poincaré's conventionalism of principles, an interpretation that has a lot to say for itself. Poincaré himself was not influenced by pragmatism, but his work does show some similar themes, such as the human contribution to knowledge exhibited in his conventionalism. René Berthelot was the first to notice the connection between Poincaré and pragmatism, and his study is groundbreaking in this regard (Berthelot 1911).

Neo-Kantianism is important because it formed a context for the work of the Pragmatists and the Vienna Circle and to Poincaré's work. It grounds the focus on the human element of knowledge and provides the basic distinctions between the a priori and empirical and the analytic and synthetic. NeoKantianism was also a direct influence on Pap's functional theory of the a priori. Indeed, Pap holds that Cassierer's interpretation of Kant is a version of the functional theory of the a priori: "Cassirer tends to assimilate Kant's doctrine of the a priori to the functional-pragmatic interpretation of the a priori" (1943a, 2006, 53). So, Pap never sees any conflict between the neo-Kantians and the pragmatists on the functional account of the a priori. He relates Lenzen's views to Kant as follows: "Lenzen is Kantian in so far as he acknowledges that universal principles enter as essential determinants into what the physicist declares as 'reality.' These 'constitutive conditions of experience,' however, are, for Lenzen, 'synthetic a priori' only in the crooked sense of being, on the one hand, empirically grounded, and on the other hand, a priori in their "constructive function"' (Pap 1946, 21). That is to say, universal principles are synthetic insofar as they are empirically grounded - they are statements about objects in the real world-but they are a priori in their function. It is only in this functional sense that such principles can be called a priori. They are neither certain nor known through a special intuition, thus sharing almost none of 
the characteristics of what has classically been called a priori knowledge. Contrary to the view of the Logical Empiricists, however, they are not simply analyzable in terms of meaning as analytic statements.

Pap and Lenzens's theory of the functional a priori is close to Reichenbach's early view (1920/1965). Reichenbach there makes a famous distinction between two meanings of a priori in Kant. On the one hand, a priori knowledge is supposed to be eternally true, and on the other hand, it is said to constitute the object of knowledge (48). Reichenbach says that we should give up the first meaning of the a priori from Kant but maintain the second, thereby allowing for a priori knowledge that has changed over time. While Kant took Euclidean metric geometry to be a priori in both senses, Reichenbach argues that in the light of Einstein's theory of relativity, metric geometry has changed but still remains constitutive in Kant's sense. Reichenbach focuses on principles of coordination, claiming that they have a unique epistemological status as a priori elements in scientific knowledge. Michael Friedman (1999, chap. 3) has shown that Reichenbach's views on the a priori changed after an exchange of letters with Schlick. Reichenbach gave up his defense of a modified Kantian a priori and embraced Schlick's empiricism.

\section{Pap's Early Articles}

Before writing his dissertation, Pap published two articles in the Journal of Philosophy and one in Philosophical Review. The most relevant one for my purposes is Pap (1944). In this article, Pap distinguishes three kinds of a priori, advocating the view that all three kinds of a priori knowledge exist. He calls the first the formal or analytic a priori, and it includes all tautologies and other analytic truths. Next is the functional a priori, statements that play the role of a priori knowledge but that are hypothetical or conditional; that is, they are "predicable of conceptual means in relation to objectives or ends of inquiry" $(1944,2006,57)$. Finally, he advocates for what he terms a material a priori, which is a synthetic a priori that is supposedly self-evident. He says that he avoids using the term 'synthetic a priori' because some of Kant's synthetic a priori is actually the functional a priori. Pap's main examples of the material a priori are the principles of logic themselves, which is a little odd, given that tautologies and other logical principles are supposed to be ipso facto analytic. Could we not define the principles of logic as analytic? In any case, Pap's point is that the principles of logic have a special status, and he is surely right about that since they must be presupposed before any inquiry into the analytic/ synthetic distinction can be started. "Thus the very analysis of what is meant by the 'formal a priori' reveals the existence of another kind of a priori without 
which the formal a priori could not even be defined. I shall call this the material a priori, avoiding the more familiar term 'synthetic,' because the latter has been ambiguously applied, by Kant, to both the material and the functional a priori. The principles of logic themselves, which we just saw to be essentially involved in the definition of the formal a priori, are materially a priori" (63-64).

Pap's insistence on the material a priori in this early article puts him at odds with both Logical Empiricism and C. I. Lewis. He acknowledges this in rather tongue-in-cheek fashion, noting that he could be accused of mystical Platonism. Rather than forthrightly embracing such mysticism, however, Pap offers a way out, an alternative to seeing logic either as given by pure intuition or as taking it to be merely conventional. Speaking of the laws of logic, Pap says:

Their truth is a matter neither of deduction nor of induction. We are then left with two alternatives: either they are self-evident, "seen" to be true in pure "Wesensanschauung," as the phenomenologists would say, or they are conventions. Even though it would certainly be more emancipated to accept the latter alternative, and to dismiss the former alternative as mystical Platonism, I venture to suggest that we are not, here, really confronted with mutually exclusive alternatives. Just as empirical laws of nature are used as conventional definitions of empirical concepts, because they are true in a non-pragmatic sense, so the principles of logic can be used as implicit definitions of logical concepts, like negation, implication etc., because they possess some kind of evidence that is independent of the use that can be made of them. $(1944,2006,63-64)$

Pap's idea here is that the principles of logic can function as first principles no matter what their epistemological status. The fact that they can be used to define the logical connectives does not show that they are "merely conventional." Even if we grant this point to Pap, however, it still leaves the selfevident character of logic to be explained. The point of the argument for the conventionalism of logic is precisely to do away with this question, that is, to get rid of the demand for an explanation of the epistemological ground of the principles of logic. It seems that Pap is still left with some commitment to a form of self-evidence, even if he is not willing to embrace it fully. In his later writings, he is likewise circumspect about the status of self-evident principles. We can only note here that Pap is committed to them.

Since I am following Pap's idea of the functional a priori here, it is his discussion of this type of a priori knowledge that is most relevant. However, Pap does no more than introduce the idea in his 1944 article, given that the majority of the article is devoted to the formal and the material a priori. Still, it is 
important to note that Pap developed the idea of the functional a priori before writing his dissertation. The main idea of the functional a priori is that one considers the role that a sentence is playing in a physical theory, rather than its origin. Certain ideas become criteria for the existence of phenomena, becoming definitions if they are used as criteria for the establishment of a correct labeling of phenomena in a category. In his 1944 article, Pap sets out the functional a priori as follows: "Any synthetic sentence, whether empirical or 'eidetic,' may be made, by a conventional act, into an analytic, formally a priori sentence. But it is usually made formally a priori, in order to be taken as functionally a priori, i. e., a hypothetically necessary presupposition, a 'procedural means,' as Dewey would say; or, as Kant called these functionally a priori principles, a 'Grundsatz,' in contradistinction to an analytically demonstrable 'Lehrsatz"' $(1944,2006,70)$. These principles are hypothetically necessary because they are the premises on which theories are founded. Their origin, whether empirical or the result of some sort of rational intuition, does not diminish their role as an analytic sentence in a physical theory. Thus, Pap focuses on the role that a sentence plays in a physical theory, rather than on the origin of the sentence.

It is important to note that even in this early article, Pap emphasizes that the three types of a priori sentences he distinguishes do not become a rigid trichotomy. Sentences can play different roles at different times.

In summary, it should be noted that, although the formal a priori, the material a priori, and the functional a priori are, as categories or epistemological predicates, distinct, they are quite compatible in the sense of being predicable of one and the same sentence. As a matter of fact, the main intent of this analysis has been to mark out the different types of epistemological status that accrue to statements in the process of scientific systematization. Synthetic statements, whether they are empirical or materially a priori, are made into analytic statements in order to be taken as "leading principles" or "conventions." Hypostatization of the categorial distinction between synthetic truth and conventional-analytic definition into existential separation, such as to think of the statements which are epistemologically qualified by these categories, as of mutually exclusive classes, gives rise to a radical misconception of science. (Pap 1944, 2006, 74)

What Pap seems to have in mind is the kind of process that he thinks takes place in the functional a priori. Sentences that have an empirical origin can be taken to be analytic if we make a decision to take the sentence as a principle 
that no empirical evidence can directly overturn. Therefore, there is certainly no permanent classification of sentences; they can change from empirical to analytic. He seems to mean something further, however, namely, that there is no strict distinction between the different types of a priori, leaving borderline cases that are hard to classify. This would presumably mean that some logical principles could seem to be merely analytic, rather than materially a priori, and vice versa, namely, that some analytic truths are close to being logical principles.

\section{Dissertation: The A Priori in Physical Theory}

Pap opens his discussion of the a priori in physical theory with the following quote from Poincaré, which was mentioned above as his motto. "Principles are conventions and disguised definitions. They are nevertheless drawn from experimental laws, these laws have been so to speak erected as principles to which our mind assigns an absolute value" (Poincaré 1913/1982, 125; translation modified; Pap quotes the original French). He then lists his other influences and states the basic insight that led him to his functional theory of the a priori. "Under the influence, first, of C. I. Lewis' 'conceptual pragmatism,' as developed in Mind and the World Order, and then of Dewey's Theory of Inquiry, I was led to develop a functional interpretation of the a priori with close regard to the methods of physics" (Pap 1946, vii). It is interesting that Pap refers to Dewey's Logic: The Theory of Inquiry (1938/1986) by its subtitle. Although Pap is informal in other citations of Dewey, as we have seen above, Pap's emphasis on the theory of inquiry is correct, given the focus of Dewey's book. The subtitle more accurately reflects the content of the book than the main title does, especially in a context in which symbolic logic is ascendant. Coming as it does, after Principia Mathematica and the rise of symbolic logic, Dewey's title seems incongruous. Of course, Dewey is standing in a long line of a succession of books on logic that we would now think of as epistemology, with Dewey's Logic being perhaps the last major work in this tradition.

Pap sets out the problem that he will discuss in his dissertation by telling why he rejects the Logical Empiricist position on a priori knowledge:

The dictum that in so far as a statement is a priori it is verbal and "asserts nothing about reality" and in so far as it is synthetic it may be refuted at any moment by experience, always left me with a sense of mental discomfort. After several attempts at rehabilitating the honorable status of "synthetic a priori" propositions had failed, the conventionalist writings of Duhem and Poincaré, and especially Victor Lenzen's The Nature of 
Physical Theory, helped me to locate the trouble. If, as methodologists, we adopt a static point of view, and examine the body of scientific propositions as it may be found systematized at a definite stage of inquiry, we will, indeed, successfully divide it into analytic and synthetic propositions, as forming mutually exclusive classes. If, however, our point of view is dynamic or developmental, we shall find that what were experimental laws at one stage come to function, in virtue of extensive confirmation by experience, as analytical rules or "conventions," in Poincaré's language, at a later stage (1946, vii).

Thus, the key insight is that the status of scientific statements can change over time and from one context to another. The result is that while there is no a priori in the traditional sense, there still are and must be scientific statements that play the role of principles and function as a priori knowledge, even if they were originally empirical.

As Pap notes, this view has its roots in Poincaré's conventionalism. Unfortunately, Poincaré's conventionalism has been open to many interpretations and controversies, so saying that Pap's theory of the a priori has Poincaré's conventionalism as a source may add more confusion and controversy than it adds clarification of Pap's view. Without engaging in a full defense of my interpretation of Poincaré's conventionalism here, I will note that there is an important distinction between the motivation for Poincaré's geometric conventionalism and his conventionalism about fundamental principles of science. Poincarés conventionalism of principles fits the reading given by Lenzen and Pap, while the geometric conventionalism does not. Poincaré thinks that some empirical laws of science can be "erected" 1 as principles that have a functionally a priori status, but geometry has a special status as being neither empirical nor a priori.

My main point here is that we can see Pap as working in a tradition, one that constitutes an alternative to Logical Empiricist orthodoxy, even if Pap is writing at the time of the heyday of Logical Empiricism and is very connected to it. On the one hand, the questions that are being posed and the distinctions that are being used are very much the same as those of the Logical Empiricists. Both share a neo-Kantian background that forms the context to these debates. On the other hand, Pap does not accept the complete elimination of a priori knowledge, as do the Logical Empiricists.

As some of his contemporary critics noted, one may wonder why Pap wants to hold onto the notion of a priori knowledge when, in many ways,

1. The French word is érigées from the verb ériger. This could mean to erect a monument, to set something up, or to establish a company. 
the functional a priori is not a priori at all in the traditional sense. It would perhaps be better to say that Pap and the pragmatists have a theory of what was formerly taken to be a priori knowledge and to drop the usage of 'a priori' altogether. I think that it is the neo-Kantian heritage that makes Pap hold onto this language. Pap does not want to break totally with Kant by rejecting the a priori outright, given that the constitutive role of the fundamental principles of scientific theories is too important to gloss over. Here is Pap's defense of his use of the term 'functional a priori':

The theory of the a priori which will, in this essay, be presented and applied to physical principles, may be called functional in so far as the a priori is characterized in terms of functions which propositions may perform in existential inquiry, no matter whether they be, on formal grounds, classified as analytic or as synthetic. It may also be called contextual; for statements of the form " $\mathrm{x}$ is a priori" or " $\mathrm{x}$ is a posteriori" (where the admissible values of $\mathrm{x}$ are propositions) will be treated as elliptical or incomplete. A proposition which is a priori in one context of inquiry, may be a posteriori in another context. (1946, viii)

Pap agrees with Dewey that the functional a priori is contextual, showing that his view has some elements of Carnap's mature position. Statements are analytic in a language for Carnap—statements are a priori or empirical in a context, according to Pap.

\section{The Analytic Functioning of Empirical Laws}

In his discussion of the "hardening" empirical generalizations to definitions, Pap opens with the distinction between real and nominal definitions. Real definitions are based on facts in the world, while nominal definitions are purely verbal. He then endorses Hilbert's notion of implicit definition of the primitive terms of geometry and extends this to cases in natural science, specifically Newtonian mechanics. The central claim of Pap's functional theory of the a priori is that empirical (and hence contingent) statements may sometimes function as temporarily fixed principles. They are taken for granted as true and used as guideposts by which phenomena are interpreted, but they can be changed later. "As inductive generalisations become increasingly confirmed they tend to be used as principles by which the 'phenomena' are interpreted. For example, within Newtonian dynamics it would hardly ever occur to a physicist to explain the negative outcome of an astronomical prediction in terms of a failure of the general equation of motion; assuming the latter to 
be valid, the discrepancy between observation and prediction will 'prove' to him that something is wrong with his assumptions concerning the initial and boundary conditions" (Pap 1946, 28). The perturbations in planetary motion might be explained by predicting the existence of an unknown planet that is causing the changes in orbit, rather than inferring that there is something wrong with the fundamental laws of motion. If a body is moving at a velocity other than $1 / 2 \mathrm{gt}^{2}$, we will assume that it is not in free fall and that forces other than gravity are acting on it. Why are such principles never called into question? Logically speaking, they can be questioned, of course, but at a given developmental stage of a science, some principles are simply taken to be true. They are no longer in question or up for grabs; rather, they are used to make predictions and to interpret phenomena.

Pap says that he will emphasize the making and functioning of a priori sentences in science, rather than focus on the ultimate distinction between a priori and empirical statements, as does Lewis (Pap 1946, 4). Lewis takes the a priori to be analytic, but Pap is closer to the truth when he says that a priori statements are empirical and then hardened into analytic statements, which is why the distinction between analytic and synthetic statements is much less clear-cut than Lewis would have us believe. Pap's recognition that there is no clear-cut distinction between analytic and synthetic statements is more defensible than Lewis's dichotomy.

Pap also criticizes Lewis for characterizing the a priori in terms of what one is willing to maintain in the face of all experience (Pap 1946, 4; see Lewis $1929 / 1956,224)$. Since Duhem has shown that it is always logically possible to hold onto a given set of ideas and to explain negative experimental results by adjusting auxiliary hypotheses, every statement could be considered a priori by this criterion, if we mean simply that it is possible to maintain the proposition. But Lewis would not seem to have such a weak criterion in mind. What we are willing to maintain is surely narrower than what is logically possible. So Pap argues that if Lewis means that it must be practically possible to hold onto a given set of ideas for them to be a priori, then it would become extremely complicated to decide whether a given statement is a priori (or analytic) or not. Pap is right, but I think that he cannot use this point to criticize Lewis. We have to own up to the fact that it is extremely difficult to decide what is a priori and what is empirical. Just as it is impossible to make a sharp divide between analytic and synthetic statements, it is also impossible to make a sharp divide between a priori and empirical statements. Indeed, Pap focuses on those empirical statements that are hardened into definitions, that is, those that are empirical at one time or in one context and function as a priori in another. So Pap is right, but he cannot use the point to criticize Lewis quite as he imagines. The problem 
that should be in focus is that Lewis thinks that it is possible to make an absolute distinction between synthetic and analytic statements, while in fact, the distinction can only be made for a certain time and in a certain context. What Pap correctly proposes is to look at the function that the sentence plays in a given physical theory, in order to determine whether the sentence is a priori or not. Pap emphasizes the process by which inductive generalizations can be taken to be definitions and hence become analytic statements. They then become a priori conventions by which scientific theory is constituted.

In a final criticism of Lewis, Pap tries to argue that there is a conflict between Lewis's claim that the a priori is analytic and his thoroughgoing fallibilism. "On the one hand, Lewis insists on the analytic or definitive nature of these 'criteria of reality.' On the other hand, he claims that, since our classificatory judgments imply an indefinite number of other classificatory judgments in terms of which they may be verified, complete verification of our classifications is impossible and hence any subsumptive judgment is a merely probable hypothesis. But these two emphases are hardly compatible" $(1946,3)$. The problem is that meaning has an empirical basis and that, as such, it is contingent. It is not clear to me that this is a real problem for Lewis, however. The solution to the apparent contradiction is that Lewis's criterion of reality needs to be taken as contingent as well. Pragmatists should be expected to take everything to be contingent and revisable, including definitions.

\section{Later Works}

One postdissertation work of Pap's that is worth considering in this survey of his philosophy of science is "Does Science Have Metaphysical Presuppositions?" which is chapter 16 of Elements of Analytic Philosophy and was reprinted in slightly abridged form in Feigl and Brodbeck's hugely influential collection (1953, 21-33). Pap's main argument in this piece is that while science has presuppositions, these should not be called metaphysical. Specifically, he says that while the presuppositions are statements of great generality, there is nothing to be gained by calling them metaphysical. This line of argument seems to me to sidestep the interesting questions, namely, what kinds of presuppositions are required in science, and what do we say about their status? Pap is surely right that the label 'metaphysics' is not important, but the status that presuppositions have as what we might call preempirical is highly important.

The most interesting section of the chapter in that regard refers to justification of presuppositions. Pap argues that they are ultimately empirical, even if we have forgotten the empirical origin of the presupposition, but that they come to be treated as a priori. "It happens all the time that a principle which 
has been highly confirmed in past inquiries comes to function as a practically unquestioned assumption in future inquiries; and if we forget the empirical background of the principle we might be tempted to regard it as a necessary or a priori truth, a genuinely metaphysical presupposition of scientific procedures" $(1949 / 1972,440)$. It is not really the case that these principles were learned empirically first and that then the origin of the knowledge was forgotten, or at least not in all cases. Sometimes a principle comes from a former scientific dispute long since resolved, as in the case of spontaneous generation, for example, but sometimes it seems difficult to imagine the empirical origin of the principle, such as in the case of Newton's first law, the principle of inertia.

\section{Poincaré's Geometric Conventionalism}

In his textbook on the philosophy of science (1962), Pap clearly follows Reichenbach's interpretation of geometric conventionalism. Pure geometry is purely formal and neither true nor false, while applied geometry is conventional in the sense that we can choose a pure geometry plus a set of coordinating definitions in order to create a physical theory. Once we have chosen a set of coordinating definitions, there is a truth of the matter of which geometry applies to physical space:

The question is: "is it a fact that the Riemannian postulates are true of physical space, and not the Euclidean postulates?" the proper answer is not so much "no" than: the question is meaningless. The postulates of a pure geometry are no statements at all, hence there is no sense in saying that they are true or false of anything. If there is an element of convention in the application of a geometry to physical space, as Poincaré emphasized, it is this: if a given set of coordinative definitions converts the postulates of a given formal geometry into empirically false statements, there are two alternative ways of amending the situation, and it is a matter of convenience which may be chosen: one might change the coordinative definitions and stick to the use of just that formal geometry; or one might stick to the coordinative definitions and look for another formal geometry which the very same coordinative definitions would convert into a true physical geometry. (Pap 1949/1972, 428)

I disagree that this is all that is going on in Poincaré's geometric conventionalism (Stump 1999). If it were, Poincaré's would have to be a thoroughgoing conventionalist, not merely a conventionalist about geometry and a few principles but about the rest of physical theory as well, which is not the case, 
as Poincaré makes abundantly clear, especially when distancing himself from the views of Le Roy in Revue de metaphysique et de morale (reprinted in The Value of Science) but also even earlier in Science and Hypothesis (1913/1982, 125). In fact, Poincaré's conventionalism about geometry and his conventionalism about principles are different, the first being based on a relational theory of space and the second on the functional theory of the a priori. Poincaré explicitly distinguishes conventions in geometry from the conventions of principles in the physical sciences (124). In adopting Reichenbach's interpretation of Poincaré's geometrical conventionalism in his later writings, Pap extends his theory of the functional a priori too far. The conventionalism of principles should be the only focus of Pap's investigation of the functional a priori.

\section{Meaning and Mathematics}

In the end, Pap does not want to say, it appears, that the synthetic a priori is real and that it is impossible to analyze all a priori statements as analytic. He takes a more ambiguous line, arguing for the functional a priori while maintaining an empirical stance. Pap is somewhat misled, I believe, by his focus on meaning, that is, his shift from the philosophy of science proper to general methods of analytic philosophy. For example, Pap insists that empirical sentences that have been hardened into principles have undergone a shift of the meaning of their terms. "Our contention that scientific truths undergo a development from contingency to analytic necessity (in Poincaré's language, experimental laws are 'erected' into 'conventions') might then be reformulated as follows: one and the same sentence which is in one context of inquiry synthetic may, in a different context of inquiry, be analytic, in virtue of a shift of meaning undergone by some of its terms" $(1946,24)$. Presumably, what is at stake here is that the meaning of a term has changed so as to include the property that is in question when the sentence becomes a criterion. So, falling at the rate of $1 / 2 \mathrm{gt}^{2}$ becomes a criterion of free fall when we no longer consider that the law of free fall might need correction and instead take any other measured rate of free fall as evidence for the existence of force acting on the body. Pap would have us then include $1 / 2 \mathrm{gt}^{2}$ in the definition of "free fall," but I do not see what is gained here by talking in terms of meaning. Why not simply say that we now have a criterion of free fall and leave our theory neutral when it comes to questions of meaning? I am suspicious of discussions of meaning because I think they play little role in science as it is practiced. Of course, terms are defined in science, but discussion of a theory of meaning belongs to linguistics and philosophy. Couching the discussion of the functional a priori in terms of meaning is not helpful and, if anything, just leads to confusion about the functional status of 
the principles of science that function as a priori elements, that is, as takenfor-granted principles.

As noted above, Pap recognizes that the distinction between analytic and synthetic statements cannot be fixed permanently and in advance of inquiry. "With regard to existential inquiry, analyticity is an ideal limit. The concepts 'analytic' and 'synthetic' are no doubt mutually exclusive, but if scientific inquiry is viewed as a continuous process, it will be seen that empirical laws converge from the status of synthetic descriptions towards the status of analytic 'criteria of reality' (it being understood, though, that 'criteria of reality' have no final status but are instrumental in further inquiry)" $(1946,26)$. I want to suggest that thinking that the analytic and the synthetic can be determined prior to and independent of empirical inquiry is a fundamental mistake made by both Lewis and Carnap. Both want to separate the formation of a language from the development of physical theory, but the course of empirical theory can itself influence what is taken to be analytic or fixed and what is taken to be synthetic or empirical. It is impossible to set out the rules for language independently of physical theory.

The role of mathematics in physical theory is a case in point. Mathematical statements did not start out as empirical and become hardened into principles that have the status of a priori knowledge. I will not attempt to answer the question of what the status of mathematics is but rather argue that the functional theory of a priori knowledge is neutral with regard to theories of the status of mathematics. Concerning logic and mathematics, Pap advocates the continuity of mathematical and physical inquiry:

We want, however, to emphasize that, in respect of this analytic functioning, there is but a difference of degree between mathematical or logical truths on the one hand, and highly warranted inductive generalisations, on the other hand. It is true that the failure of a physical prediction would never be explained by casting suspicion upon the logical and mathematical principles that are implicitly assumed in the deduction of testable consequences. But the same holds true, though to a less degree, with respect to fundamental physical principles such as the general equation of motion or the conservation principles. If, therefore, the validity of logicomathematical truths is to be sui generis, their apriority cannot be defined in terms of their prescriptive function in empirical inquiry. $(1946,28)$

This is not quite to say that mathematics is empirical but rather that the function of mathematics in physical theory is very similar to that of fundamental principles that are empirical in origin. Mathematical truths are found by conceptual 
practices and "hardened" when they are taken up in physical theory where they are taken for granted as true in the new context. The ultimate ground of pure mathematics, whether it be logic, intuition, or syntax, is not important in this context. The functionally a priori role of mathematics in physical theory is consistent with all three of the classic standpoints in the philosophy of mathematics, and there is no reason that it would not be compatible with others as well. The important point here is the role that mathematics plays in physical theory, not the ultimate status of mathematics.

\section{Conclusion}

The epistemological status of logic, mathematics, and even some fundamental laws of nature have always been problematic. They do not seem to be empirical or to be simply a matter of definition. However, taking them to be known a priori is not viable either, given that there is no intuitive, certain knowledge of nature. The functional theory of the former a priori addresses this dilemma by focusing on the special epistemological status that fundamental laws of nature and parts of mathematics have as constitutive parts of physical theory. These elements of physical theory must be assumed before it is even possible to begin inquiry into a given science. It is this constitutive function that gives principles of physics and parts of mathematics their distinctive epistemological status, one that is missed by strict empiricism and that is masked by holism.

I have presented an overview of Pap's functional theory of a priori knowledge and shown it to be grounded in pragmatism and neo-Kantianism and to be a solution to the problem of the epistemic status of mathematics and certain fundamental principles of physical theory. The pragmatic conception of the a priori, developed by Dewey and Lewis, and the function theory of the a priori, developed by Pap, present alternatives to the Logical Empiricist conception of a priori knowledge and thereby to the dominant philosophy of science in the postwar period. These alternatives have been largely forgotten, and even though they were discussed, they never fully took hold in the philosophy of science. I hope to contribute to reviving a discussion of them now. If in Germany, after the excesses of idealism, there was a "back to Kant" movement, then it is high time we saw a "back to pragmatism" movement in the philosophy of science, to counter the excesses of Logical Positivism and of realism.

\section{REFERENCES}

Berthelot, René. 1911. Un romantisme utilitaire: Étude sur le Mouvement Pragmatiste; le pragmatisme chez Nietzsche et chez Poincaré. Vol. 1. Paris: Alcan. 
Dewey, John. 1938/1986. Logic: The Theory of Inquiry. New York: Holt, Rinehart \& Winston. Repr. Collected Works of John Dewey: The Later Works, vol. 12, Carbondale: Southern Illinois University Press.

Feigl, Herbert, and May Brodbeck, eds. 1953. Readings in the Philosophy of Science. New York: Appleton-Century-Crofts.

Friedman, Michael. 1999. Reconsidering Logical Positivism. Cambridge: Cambridge University Press.

- 2001. Dynamics of Reason: The 1999 Kant Lectures at Stanford University. Stanford, CA: CSLI.

Lenzen, Victor. 1931. The Nature of Physical Theory: A Study in Theory of Knowledge. New York: Wiley.

Lewis, Clarence Irving. 1923/1970. “A Pragmatic Conception of the A Priori.” In Collected Papers of Clarence Irving Lewis, ed. J. D. Goheen and J. John L. Mothershead, 231-39. Stanford, CA: Stanford University Press.

_- 1929/1956. Mind and the World Order: Outline of a Theory of Knowledge. New York: Dover.

$\rightarrow$ Pap, Arthur. 1943a. "On the Meaning of Necessity." Journal of Philosophy 40 (17): 449-58.

$\rightarrow$ 1943b. "On the Meaning of Universality." Journal of Philosophy 40 (19): 505-14.

$\rightarrow$ - 1944. "The Different Kinds of A Priori." Philosophical Review 13 (5): 465-84.

- 1946. The A Priori in Physical Theory. New York: King's Crown.

- 1949/1972. Elements of Analytic Philosophy. Repr., New York: Hafner.

1962. An Introduction to the Philosophy of Science. New York: Macmillan.

- 2006. The Limits of Logical Empiricism: Selected Papers of Arthur Pap. Ed. Alfons Keupink and Sanford Shieh. Dordrecht: Springer.

Peirce, Charles S. 1958-60. Collected Papers. Ed. Charles Hartshorne and Paul Weiss. Cambridge, MA: Belknap.

Poincaré, Henri. 1913/1982. The Foundations of Science: Science and Hypothesis, the Value of Science, Science and Method. Washington, DC: University Press of America.

Reichenbach, Hans. 1920/1965. The Theory of Relativity and A Priori Knowledge. Berkeley: University of California Press.

Reisch, George A. 2005. How the Cold War Transformed Philosophy of Science to the Icy Slopes of Logic. Cambridge: Cambridge University Press.

Stump, David J. 1999. "Poincaré, Jules Henri." In Routledge Encyclopedia of Philosophy, ed. E. Craig, 478-83. London: Routledge. 
